\title{
Effect of scopoletin on lipoprotein lipase activity in 3T3-L1 adipocytes
}

\author{
JEONG-YEH YANG ${ }^{1}$, JEUNG-HYUN KOO ${ }^{1}$, HA-YONG YOON ${ }^{1}$, JU-HYUNG LEE ${ }^{2}$, \\ BYUNG-HYUN PARK ${ }^{1,3}$, JONG-SUK KIM ${ }^{1,3}$, MYUNG S. CHI ${ }^{1,4}$ and JIN-WOO PARK ${ }^{1,3}$ \\ Departments of ${ }^{1}$ Biochemistry and ${ }^{2}$ Preventive Medicine, Medical School, \\ ${ }^{3}$ Institute for Medical Sciences, Chonbuk National University, Jeonju, 561-756 Chonbuk, Korea
}

Received May 17, 2007; Accepted June 27, 2007

\begin{abstract}
Hypertriglyceridemia is an independent risk factor of cardiovascular diseases. It is caused by the imbalance between hepatic triglyceride production and peripheral removal. Lipoprotein lipase (LPL) plays a central role in the removal of plasma triglyceride. During the screening of possible anti-dyslipidemic drugs, we observed that scopoletin (6-methoxy-7-hydroxycoumarin) significantly increased LPL activity in adipocytes. Scopoletin increased LPL activity in culture medium of 3T3-L1 adipocytes in dose- and timedependent manners. It did not release LPL from the adipocyte membrane and, instead, increased the LPL mRNA level, suggesting transcriptional control. Scopoletin also partially reversed tumor necrosis factor- $\alpha$-induced suppression of LPL activity. These results suggest the possible action of scopoletin as a facilitator of plasma triglyceride clearance.
\end{abstract}

\section{Introduction}

Evidence suggests that elevated serum triglyceride (TG) levels likely contribute independently to the increased risk of cardiovascular disease (1). Hypertriglyceridemia frequently coexists with other conditions that affect the cardiovascular disease risk, such as depressed high-density lipoprotein, obesity, metabolic syndrome, proinflammatory and prothrombotic biomarkers, and type 2 diabetes (2). Furthermore, severe hypertriglyceridemia is associated with an increased risk of acute pancreatitis, irrespective of its effect on the risk of cardiovascular disease (3). Therefore, a treatment that lowers plasma triglyceride levels would be of great value in protection against hypertriglyceridemia-associated metabolic abnormalities.

Correspondence to: Dr Jin-Woo Park, Department of Biochemistry, Chonbuk National University Medical School, Jeonju, 561-756 Chonbuk, Korea

E-mail: jinwoo@chonbuk.ac.kr

Present Address: ${ }^{4}$ Human Nutrition Research Program, Lincoln University, Jefferson City, MO 65101, USA

Key words: scopoletin, lipoprotein lipase, adipocyte
Lipoprotein lipase (LPL, EC 3.1.1.34) is an enzyme that hydrolyses TG of chylomicron and very low-density lipoprotein into fatty acids and glycerol. The released fatty acids are taken up mainly by the heart, skeletal muscle and adipose tissue, and used for metabolic fuel or substrate for reesterification into TG. Thus, LPL is an important enzyme for the regulation of serum TG concentration, and also for the metabolic homeostasis between fat-utilizing and fat-storing tissues (4).

Physiologically, LPL is synthesized and secreted by adipocytes and myocytes. After being synthesized, LPL becomes glycosylated, dimerized and then transported to the luminal surface of the vascular endothelial cells (5-7). The LPL attached on the heparin sulfate of endothelial cells can be released into plasma by heparin (8). The control of LPL in adipose tissue is very complex, involving several hormones $(9,10)$. In general, cortisol and insulin appear to promote lipid accumulation by increasing the activity of LPL, while growth hormone and estrogen appear to exert opposite effects (11). Insulin treatment of 3T3-L1 adipocytes has been shown to increase the level of cellular and heparin-releasable LPL activity through posttranscriptional and posttranslational mechanisms (12). The expression of LPL is also regulated during a number of pathological conditions, such as atherosclerosis, diabetes, cachexia and infection $(9,10)$.

Scopoletin (6-methoxy-7-hydroxycoumarin) is a phenolic coumarin and has previously been reported to have hepatoprotective (13), antioxidant (14), spasmolytic (15) activities, and an inhibitory effect on nitric oxide synthesis (16). Recently, we reported that scopoletin induced apoptosis in promyelocytic leukemic cells through activation of $\mathrm{NF \kappa B}$ and caspase-3 (17). In this study, we observed that scopoletin greatly increased LPL activity in 3T3-L1 adipocytes at the transcriptional level. It did not affect the LPL release from adipocytes and partially reversed LPL suppression by tumor necrosis factor- $\alpha$. The beneficial effects of synthetic LPL activator, NO-1886, has already been reported in hypertriglyceridemia (18) and cachexia (19). Scopoletin may also act as a facilitator of plasma triglyceride clearance.

\section{Materials and methods}

Cell culture. 3T3-L1 cells obtained from American Type Culture Collection (ATCC CCL 92.1) were grown to 


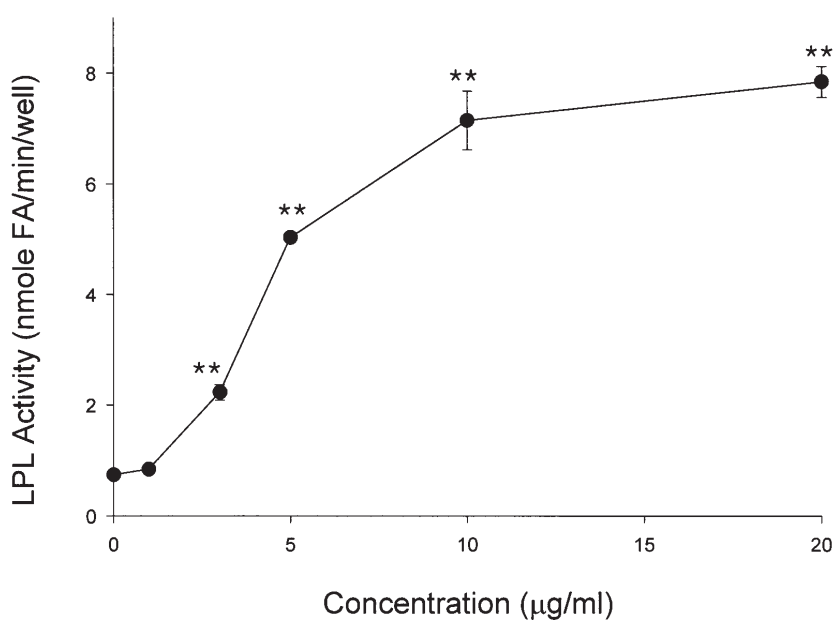

Figure 1. Dose-dependent increase of LPL activity by scopoletin. 3T3-L1 adipocytes were incubated with various concentrations of scopoletin for $6 \mathrm{~h}$, and LPL activities were determined from culture medium. Data were expressed as the mean $\pm \mathrm{SE}$ of three separate experiments. ${ }^{* *} \mathrm{P}<0.01$.

confluence in 24-well culture plates with standard medium (Dulbecco's modified Eagle's medium containing 10\% fetal bovine serum, $100 \mathrm{U} / \mathrm{ml}$ penicillin, $0.1 \mathrm{mg} / \mathrm{ml}$ streptomycin, and $0.25 \mu \mathrm{g} / \mathrm{ml}$ amphotericin B) as described previously (20). Confluent cells were stimulated to differentiate into adipocytes by supplementing the standard medium with $1 \mu \mathrm{M}$ dexamethasone, $10 \mu \mathrm{g} / \mathrm{ml}$ insulin, and $0.5 \mathrm{mM}$ isobutylmethylxanthine for 2 days. The medium was then replaced with standard medium containing $5 \mu \mathrm{g} / \mathrm{ml}$ insulin and was changed every 2 days. The cultured cells were used for experiments within 5-6 days after confluence.

Assay of LPL activity. At the end of the experiment, medium was harvested, and the secreted LPL activity was determined as described previously (21). A stock triacylglycerol emulsion containing $5 \mathrm{mCi}$ of tri $\left[9,10(\mathrm{n})-{ }^{3} \mathrm{H}\right]$ oleoylglycerol (Amersham, Buckinghamshire, UK), 1.13 mmole of trioleoylglycerol, $60 \mathrm{mg}$ of 1- $\alpha$-phosphatidylcholine (bovine liver) and $9 \mathrm{ml}$ of glycerol was prepared according to the method of NilssonEhle and Schotz (22). Before assay, 1 vol of the stock emulsion, $19 \mathrm{vol}$ of $3 \%$ bovine serum albumin in $0.2 \mathrm{M}$ Tris$\mathrm{HCl}$ buffer ( $\mathrm{pH} 8.1$ ) and $5 \mathrm{vol}$ of heat-inactivated fasted rat serum (heated at $60^{\circ} \mathrm{C}$ for $30 \mathrm{~min}$ ) were mixed and incubated for $30 \mathrm{~min}$. For assay, $100 \mu \mathrm{l}$ of this activated substrate mixture was added to the same amount of enzyme solution and incubated at $37^{\circ} \mathrm{C}$ for $60 \mathrm{~min}$. Released fatty acids were extracted and its radioactivity was measured.

Reverse transcription-polymerase chain reaction (RT-PCR). Total cellular RNA was prepared using Trizol solution (Gibco-BRL, Paisley, UK) according to the manufacturer's instructions. After the preparation of cDNA with oligo(dT) 16 as a reverse transcriptase primer from the extracted RNA, amplification with PCR was performed using the GeneAmp kit (Perkin Elmer, Waltham, MA) according to the manufacturer's manual. The oligonucleotide primers used for PCR are as follows: LPL upstream, 5'-TCT TGA TTT ACA CGG AGG TG-3'; downstream, 5'-TCT TGT TTG TTT GTC CAG TG-3'; actin upstream, 5'-ACC GTG AAA AGA TGA

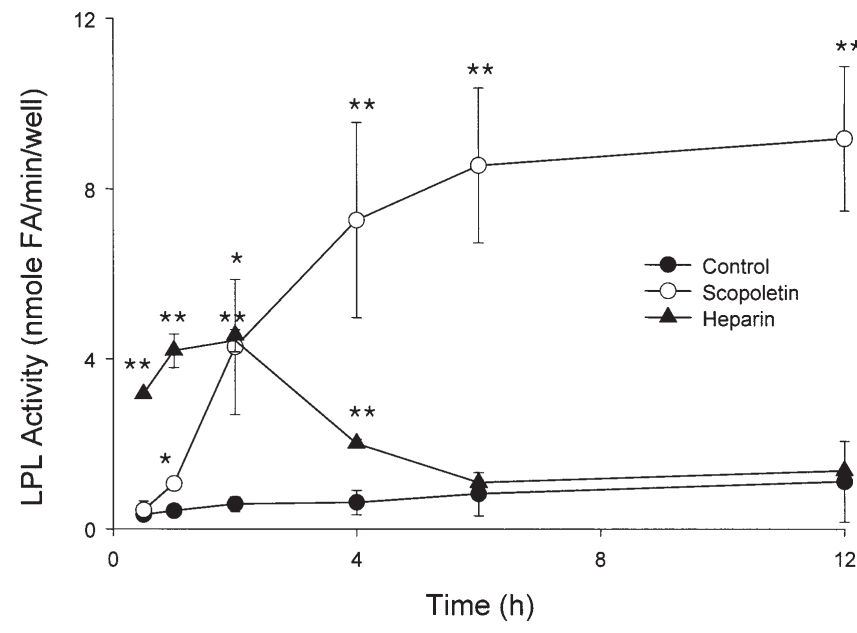

Figure 2. Time-dependent increase of LPL activity by scopoletin or heparin. 3T3-L1 adipocytes were incubated with $3 \mu \mathrm{g} / \mathrm{ml}$ heparin or $10 \mu \mathrm{g} / \mathrm{ml}$ of scopoletin for the indicated times, and LPL activities were determined from culture medium. Data were expressed as the mean \pm SE of three separate experiments. ${ }^{*} \mathrm{P}<0.05$ and ${ }^{* *} \mathrm{P}<0.01$ vs. control.

CCC AG-3'; and downstream, 5'-TAC GGA TGT CAA CGT CAC AC-3'. Each cDNA amplification used the product of $\sim 1 \mu \mathrm{g}$ of total RNA. The reaction was cycled 26 times through $30 \mathrm{sec}$ at $94^{\circ} \mathrm{C}, 45 \mathrm{sec}$ at $60^{\circ} \mathrm{C}$, and $45 \mathrm{sec}$ at $72^{\circ} \mathrm{C}$. Fifty percent of reaction mixture was analyzed by electrophoresis on $1.5 \%$ agarose gels and stained by ethidium bromide. To check the reproducibility of the results, each experiment was carried out more than three times.

Statistical analysis. Statistical analysis of the data was performed by ANOVA and Duncan's test, and differences of $\mathrm{P}<0.05$ were considered statistically significant.

\section{Results}

3T3-L1 adipocytes were cultured for $6 \mathrm{~h}$ in the medium containing $0-20 \mu \mathrm{g} / \mathrm{ml}$ scopoletin, and LPL activity was measured in the medium. Treatment of cells with scopoletin caused a dose-dependent increase in LPL activity, and reached to a near peak level at a concentration of $10 \mu \mathrm{g} / \mathrm{ml}$ scopoletin (Fig. 1). Scopoletin did not affect the LPL activity assay itself (data not shown).

The accumulated LPL activity in the culture medium of cells treated with scopoletin increased with time and was much higher compared to that of the control (Fig. 2). Cellular LPL activity corresponds to the sum of LPL activity in the intracellular and cell-surface compartments. The LPL present at the cell-surface compartment was released by heparin, and the level of activity remaining in the cells after heparin treatment corresponded to that of the intracellular compartment. As LPL activity of scopoletin-containing medium was greatly increased, the possibility of heparin-like LPL release was investigated. To prevent the cellular synthesis and transport of LPL protein to the plasma membrane, cells were incubated at $4^{\circ} \mathrm{C}$. In the presence of heparin, the release of LPL into the medium was increased 8 -fold within $30 \mathrm{~min}$, whereas the level of the released LPL activity of scopoletintreated cells was negligible, almost the same as that of the 


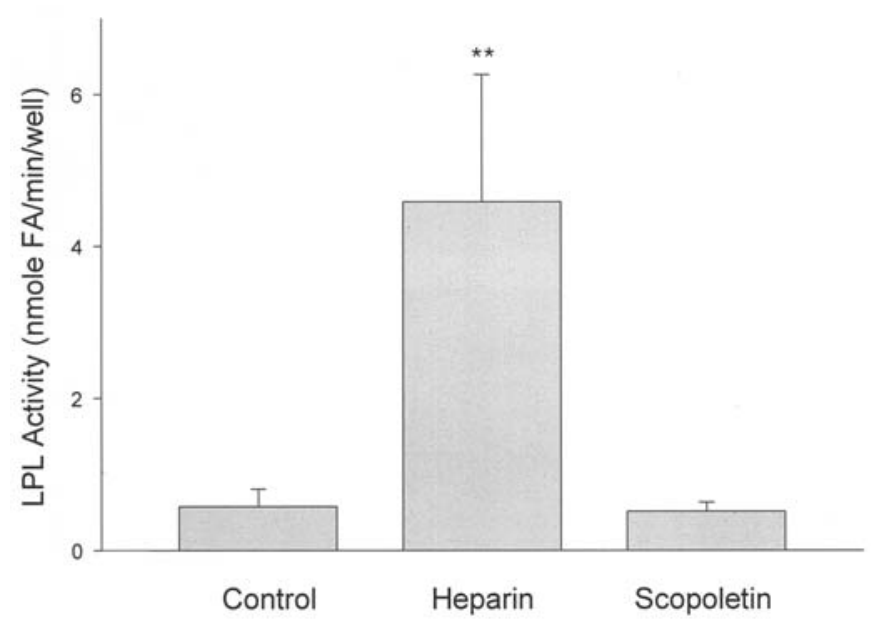

Figure 3. Release of cell-bound LPL by heparin and scopoletin. 3T3-L1 adipocytes were incubated in the presence or absence of $3 \mu \mathrm{g} / \mathrm{ml}$ heparin or $10 \mu \mathrm{g} / \mathrm{ml}$ of scopoletin for $30 \mathrm{~min}$ at $4^{\circ} \mathrm{C}$, and LPL activities were determined from culture medium. Data were expressed as the mean $\pm \mathrm{SE}$ of three separate experiments. ${ }^{* *} \mathrm{P}<0.01$ vs. control.

0

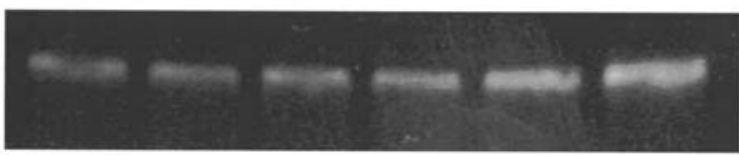

Actin

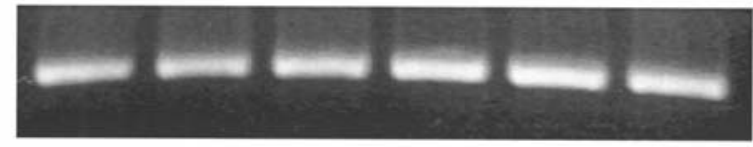

Figure 4. Time-dependent increase of LPL mRNA by scopoletin. 3T3-L1 adipocytes were incubated with scopoletin, and mRNA of LPL was visualized by RT-PCR. Lanes 1-6 represent the treatment of $10 \mu \mathrm{g} / \mathrm{ml}$ of scopoletin for $0,1,3,6,12$, and $24 \mathrm{~h}$, respectively. The result represents the typical one from three separate experiments with similar outcomes.

control (Fig. 3). When cells were incubated with heparin at $37^{\circ} \mathrm{C}$, medium LPL activity was rapidly increased until $2 \mathrm{~h}$ and began to decline and reached the control level at $6 \mathrm{~h}$ (Fig. 2). This might have been due to the initial release of LPL by heparin following inactivation of released LPL in the medium. In the case of scopoletin treatment, the initial increase in LPL within 30 min was absent and the increase in LPL activity was much slower than that of heparin-treated cells. Also, no late decline in medium LPL activity was observed (Fig. 2); rather it increased until $12 \mathrm{~h}$.

As LPL plays a critical role in body energy metabolism, its activity is tightly regulated at various levels including the transcriptional, translational and post-translational (9). To assess the change in mRNA, the cellular level of LPL mRNA was visualized by RT-PCR after treatment of cells with $10 \mu \mathrm{g} /$ $\mathrm{ml}$ of scopoletin for various times. As presented in Fig. 4, LPL mRNA was significantly increased by treatment with scopoletin in a time-dependent manner, indicating that the effect of scopoletin on the increase in LPL activity occurs at the transcriptional level.

The acute decrease in LPL activity in sepsis is caused by the action of several cytokines. Among the various cytokines,

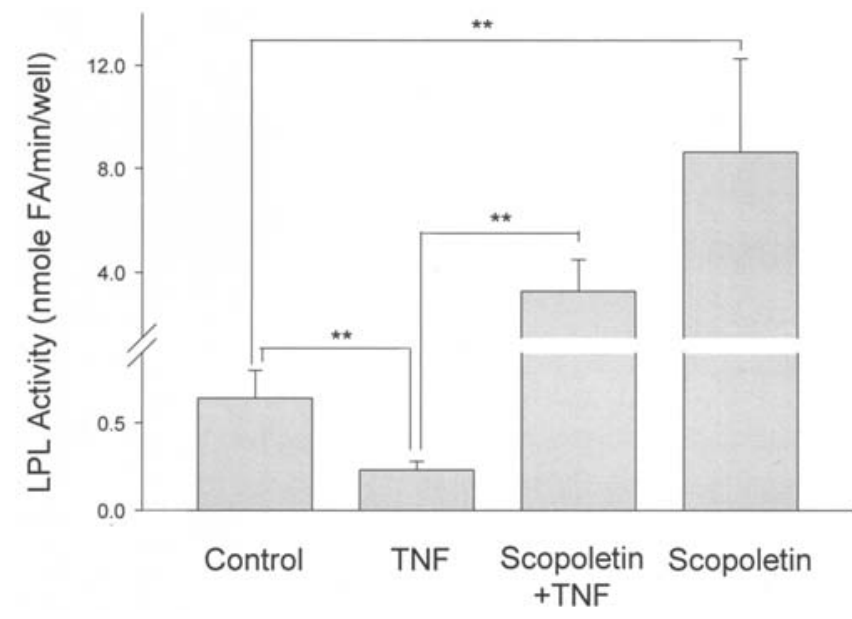

Figure 5. Effect of scopoletin on TNF-induced suppression of LPL activity. 3T3-L1 adipocytes were incubated with $10 \mathrm{ng} / \mathrm{ml}$ of TNF for $12 \mathrm{~h}$ in the presence or absence of $10 \mu \mathrm{g} / \mathrm{ml}$ of scopoletin during the final $6 \mathrm{~h}$ of incubation. LPL activity accumulated in the medium during the final $6 \mathrm{~h}$ of incubation was determined. Data were expressed as the mean \pm SE of three separate experiments. ${ }^{* *} \mathrm{P}<0.01$.

tumor necrosis factor- $\alpha$ (TNF) has been known as one of the key suppressors of adipose tissue LPL in vivo as well as in cultured adipocytes (23). When cells were treated with TNF for $12 \mathrm{~h}$, LPL activity, accumulated in the medium during the final $6 \mathrm{~h}$, was reduced to $36 \pm 14 \%$ compared with values from the control (Fig. 5). In the presence of scopoletin during the final $6 \mathrm{~h}$ of the 12-h TNF treatment, LPL activity was significantly increased by 14-fold, but the magnitude of the increase was smaller than the response with scopoletin without TNF.

\section{Discussion}

Extrahepatic parenchymal cells including adipocytes and myocytes synthesize and secrete LPL, and secreted LPL is transferred to the luminal surface of capillaries where it acts (9). LPL is attached to capillary endothelium by heparan sulfate proteoglycan and can be released into the blood stream by injection of heparin (8). LPL synthesized by adipocytes is also attached to the adipocyte membrane via heparin sulfate before secretion into medium (9).

The present study showed that scopoletin produced timeand dose-dependent increases in LPL secretion in cultured adipocytes, accompanied by an increase in LPL mRNA. The source of this LPL may be newly synthesized LPL, as the biosynthetic half-time for LPL in 3T3-L1 adipocytes has been reported to be $1 \mathrm{~h}$ (24). A peak in LPL release was demonstrated within $30 \mathrm{~min}$ after heparin treatment of the 3T3-L1 cells, and this maximal activity returned to near basal levels within $6 \mathrm{~h}$. The slower time course of LPL release by scopoletin and sustained high LPL activity in the medium even after $6 \mathrm{~h}$ suggests that scopoletin induces release of LPL from a cellular compartment, not from a heparin-releasable membrane compartment. Since it has been shown that there is a large intracellular pool of inactive, probable monomeric LPL, it is possible that this inactive pool of LPL is readily activated and released into the medium (24). However, as shown in Figs. 2 and 4, scopoletin induced a time-dependent increase in LPL mRNA in the 3T3-L1 adipocytes and 
enzyme activity in the medium, which suggests that transcriptional activation of LPL leads to increased LPL activity in the medium.

One of the major and early responses of host metabolism to infection is an increase in circulating triglyceride concentration. Hypertriglyceridemia in infection is due to both an increase in hepatic secretion of very low-density lipoprotein (25) and alterations in the rate of clearance of triglyceride, which is brought about by a cytokine-mediated reduction in LPL activity in nearly all tissues (23). Cytokines, in particular TNF, interferon, leukemia inhibitory factor, and interleukin (IL)-1, IL-6, and IL-11, are believed to be involved in the suppression of LPL that occurs in sepsis and endotoxemia (9). In vivo administration of TNF to rats decreased adipose tissue LPL activity within $6 \mathrm{~h}$ (26). TNF also led to a decline in LPL activity and mRNA levels in rat adipose tissue and 3T3-L1 adipocytes (27). As the beneficial effects of synthetic LPL activator on cachexia (19) have already been reported, we tried to investigate the effect of scopoletin on TNF-induced suppression of LPL activity in adipocytes. TNF-induced suppression of LPL activity was completely abolished by cotreatment with scopoletin, but LPL activity did not reach a similar level as that reached with scopoletin treatment without TNF.

Among the medications used for hypertriglyceridemia, niacin acts mainly through the inhibition of hepatic LDL secretion, and fibric acid derivatives are well known to act through the increase of LPL activity (28). Among the several lipid-lowering drugs under development, NO-1886 is reported to act through LPL activation (29) and is effective in hypertriglyceridemia $(18,30)$, atherosclerosis $(31)$ and cachexia (19). However, LPL is involved in whole body triglyceride partitioning according to the energy balance (32), and macrophage-derived LPL plays a pro-atherogenic role, whereas the enzyme expressed by the muscle and adipose tissue acts in an anti-atherogenic manner by improving the circulating lipoprotein profile (33). Therapeutic approaches should therefore seek a tissue-specific regulation of LPL.

In the present study, we proved that scopoletin increases LPL activity at the transcriptional level and partially reverses the TNF-induced suppression of LPL activity in 3T3-L1 adipocytes. Even though further studies are needed for elucidating the mechanism of action in adipocytes and in vivo studies, we believe that scopoletin has potential benefit for the treatment of hypertriglyceridemia and related disorders.

\section{Acknowledgements}

This study was supported by the Basic Research Program (R01-2002-000-00190-0) of KOSEF and partly by Chonbuk National University.

\section{References}

1. Yuan G, Al-Shali KZ and Hegele RA: Hypertriglyceridemia: its etiology, effects and treatment. Can Med Assoc J 176: 1113-1120, 2007.

2. Rapp RJ: Hypertriglyceridemia: a review beyond low-density lipoprotein. Cardiol Rev 10: 163-172, 2002.

3. Gan SI, Edwards AL, Symonds CJ and Beck PL: Hypertriglyceridemia-induced pancreatitis: A case-based review. World J Gastroenterol 12: 7197-7202, 2006.
4. Stein Y and Stein O: Lipoprotein lipase and atherosclerosis. Atherosclerosis 170: 1-9, 2003.

5. Blanchette-Mackie EJ, Masuno H, Dwyer NK, Olivecrona T and Scow RO: Lipoprotein lipase in myocytes and capillary endothelium of heart: immunocytochemical study. Am J Physiol 256: E818-E828, 1989.

6. Masuno H, Schultz CJ, Park JW, Blanchette-Mackie EJ, Mateo C and Scow RO: Glycosylation, activity and secretion of lipoprotein lipase in cultured brown adipocytes of newborn mice. Effect of tunicamycin, monensin, 1-deoxymannojirimycin and swainsonine. Biochem J 277: 801-809, 1991.

7. Park JW, Oh MS, Yang JY, et al: Glycosylation, dimerization, and heparin affinity of lipoprotein lipase in 3T3-L1 adipocytes. Biochim Biophys Acta 1254: 45-50, 1995.

8. Berryman DE and Bensadoun A: Heparan sulfate proteoglycans are primarily responsible for the maintenance of enzyme activity, binding, and degradation of lipoprotein lipase in Chinese hamster ovary cells. J Biol Chem 270: 24525-24531, 1995.

9. Enerback S and Gimble JM: Lipoprotein lipase gene expression: physiological regulators at the transcriptional and posttranscriptional level. Biochim Biophys Acta 1169: 107-125, 1993.

10. Mead JR, Irvine SA and Ramji DP: Lipoprotein lipase: structure, function, regulation, and role in disease. $\mathrm{J}$ Mol Med 80: 753-769, 2002.

11. Bjorntorp P: The regulation of adipose tissue distribution in humans. Int J Obes Relat Metab Disord 20: 291-302, 1996.

12. Semenkovich CF, Wims M, Noe L, Etienne J and Chan L: Insulin regulation of lipoprotein lipase activity in 3T3-L1 adipocytes is mediated at posttranscriptional and posttranslational levels. J Biol Chem 264: 9030-9038, 1989.

13. Kang SY, Sung SH, Park JH and Kim YC: Hepatoprotective activity of scopoletin, a constituent of Solanum lyratum. Arch Pharm Res 21: 718-722, 1998.

14. Shaw CY, Chen CH, Hsu CC, Chen CC and Tsai YC: Antioxidant properties of scopoletin isolated from Sinomonium acutum. Phytother Res 17: 823-825, 2003.

15. Oliveira EJ, Romero MA, Silva MS, Silva BA and Medeiros IA: Intracellular calcium mobilization as a target for the spasmolytic action of scopoletin. Planta Med 67: 605-608, 2001.

16. Kang TH, Pae HO, Jeong SJ, et al: Scopoletin: an inducible nitric oxide synthesis inhibitory active constituent from Artemisia feddei. Planta Med 65: 400-403, 1999.

17. Kim EK, Kwon KB, Shin BC, et al: Scopoletin induces apoptosis in human promyeloleukemic cells, accompanied by activations of nuclear factor $\kappa \mathrm{B}$ and caspase-3. Life Sci 77: 824-836, 2005.

18. Hara T, Cameron-Smith D, Cooney GJ, Kusunoki M, Tsutsumi K and Storlien LH: The actions of a novel lipoprotein lipase activator, NO-1886, in hypertriglyceridemic fructose-fed rats. Metabolism 47: 149-153, 1998.

19. Ohara M, Tsutsumi K and Ohsawa N: Suppression of carcass weight loss in cachexia in rats bearing Leydig cell tumor by the novel compound NO-1886, a lipoprotein lipase activator. Metabolism 47: 101-105, 1998.

20. Lee JH, Kim KA, Kwon KB, et al: Diallyl disulfide accelerates adipogenesis in 3T3-L1 cells. Int J Mol Med 20: 59-64, 2007.

21. Park JW, Lee SY, Yang JY, et al: Effect of carbonyl cyanide m-chlorophenylhydrazone (CCCP) on the dimerization of lipoprotein lipase. Biochim Biophys Acta 1344: 132-138, 1997.

22. Nilsson-Ehle P and Schotz MC: A stable, radioactive substrate emulsion for assay of lipoprotein lipase. J Lipid Res 17: 536-541, 1976.

23. Feingold KR, Marshall M, Gulli R, Moser AH and Grunfeld C: Effect of endotoxin and cytokines on lipoprotein lipase activity in mice. Arterioscler Thromb 14: 1866-1872, 1994.

24. Olivecrona T, Chernick SS, Bengtsson-Olivecrona G, Garrison M and Scow RO: Synthesis and secretion of lipoprotein lipase in 3T3-L1 adipocytes; Demonstration of inactive forms of lipase in cells. J Biol Chem 262: 10748-10759, 1987.

25. Lanza-Jacoby S, Phetteplace H, Sedkova N and Knee G: Sequential alterations in tissue lipoprotein lipase, triglyceride secretion rates, and serum tumor necrosis factor $\alpha$ during Escherichia coli bacteremic sepsis in relation to the development of hypertriglyceridemia. Shock 9: 46-51, 1998.

26. Semb H, Peterson J, Tavernier J and Olivecrona T: Multiple effects of tumor necrosis factor on lipoprotein lipase in vivo. J Biol Chem 262: 8390-8394, 1987. 
27. Mackay AG, Oliver JD and Rogers MP: Regulation of lipoprotein lipase activity and $\mathrm{mRNA}$ content in rat epididymal adipose tissue in vitro by recombinant tumour necrosis factor. Biochem J 269: 123-126, 1990.

28. Mahley RW and Bersot TP: Drug therapy for hypercholesterolemia and dyslipidemia. In: Goodman and Gilman's The Pharmacological Basis of Therapeutics. Hardman JG, Limberd LE and G. GA (eds). McGraw-Hill, New York, pp971-1002, 2001.

29. Yin $\mathrm{W}$ and Tsutsumi K: Lipoprotein lipase activator NO-1886. Cardiovasc Drug Rev 21: 133-142, 2003
30. Yin W, Yuan Z, Tsutsumi K, et al: A lipoprotein lipasepromoting agent, NO-1886, improves glucose and lipid metabolism in high fat, high sucrose-fed New Zealand white rabbits. Int J Exp Diabesity Res 4: 27-34, 2003.

31. Yin W, Tsutsumi K, Yuan Z and Yang B: Effects of the lipoprotein lipase activator NO-1886 as a suppressor agent of atherosclerosis in aorta of mild diabetic rabbits. ArzneimittelForschung 52: 610-614, 2002.

32. Bensadoun A: Lipoprotein lipase. Annu Rev Nutr 11: 217-237, 1991.

33. Mead JR and Ramji DP: The pivotal role of lipoprotein lipase in atherosclerosis. Cardiovasc Res 55: 261-269, 2002. 